\title{
Correction to: Ornithogalum gulnariensis (Asparagaceae), a new species from southern Anatolia, Turkey
}

\author{
Hakkı Demirelma ${ }^{1}$ \\ Correction to: KEW BULLETIN (2020) 75: 18 \\ https://doi.org/10.1007/S12225-020-9877-3
}

The acknowledgment text was omitted from the original version in error.

\section{Acknowledgements}

We would like to thank the Scientific and Technological Research Council of Turkey (TÜBITTAK-Project no: 110T948) for financial support.

\section{Publisher's Note}

Springer Nature remains neutral with regard to jurisdictional claims in published maps and institutional affiliations. 